BULLETIN Bulletin hispanique

HISPANIQUE Université Michel de Montaigne Bordeaux

$119-2 \mid 2017$

La Égloga renacentista en el Reino de Nápoles

\title{
De cómo el pastor Endimión mudó en la ninfa
}

\section{Enaria}

del Canzoniere a la Methamorphosi de Cariteo

M. Isabel Segarra Añón

\section{OpenEdition}

\section{Journals}

Edición electrónica

URL: http://journals.openedition.org/bulletinhispanique/5034

DOI: 10.4000/bulletinhispanique.5034

ISSN: 1775-3821

Editor

Presses universitaires de Bordeaux

Edición impresa

Fecha de publicación: 1 diciembre 2017

Paginación: 459-476

ISBN: 979-10-300-0218-8

ISSN: 0007-4640

\section{Referencia electrónica}

M. Isabel Segarra Añón, «De cómo el pastor Endimión mudó en la ninfa Enaria», Bulletin hispanique [En línea], 119-2 | 2017, Publicado el 28 diciembre 2020, consultado el 15 enero 2021. URL: http:// journals.openedition.org/bulletinhispanique/5034 ; DOI: https://doi.org/10.4000/bulletinhispanique 5034 


\title{
De cómo el pastor Endimión mudó en la ninfa Enaria: del Canzoniere a la Methamorphosi de Cariteo
}

\author{
M. Isabel Segarra AÑón \\ Universitat de Barcelona-INB Barcelona
}

L'article propose une réflexion nouvelle sur la dernière période de l'œuvre de Cariteo (Benet Garret, 1450-1514) et sur ses implications littéraires et politiques. L'auteur y analyse, d'une part, le passage du pétrarquisme à l'hermétisme et à l'allégorie dans le Libro de la Metamorphosi et montre, d'autre part, comment la mythologie parthénopéenne, littérairement fonctionnelle, se substitue au code bucolique de Sannazaro.

Mots-clés: pétrarchisme, Cariteo, églogue, Sannazaro, mythologie parthénopéene, Humanisme à Naples et Ischia, politique et poésie.

El artículo propone nuevas reflexiones sobre el último período de la obra de Cariteo (Benet Garret, 1450-1514) y sus implicaciones literarias y políticas. Se analiza el paso del petrarquismo al hermetismo y la alegoría en el Libro de la Methamorphosi, así como la sustitución del código bucólico de Sannazaro por la funcionalidad literaria de la mitología partenopea.

Palabras clave: petrarquismo, Cariteo, égloga, Sannazaro, mitología partenopea, Humanismo en Nápoles e Ischia, política y poesía.

This paper proposes new considerations about the last period of Cariteo's poetry (Benet Garret, 1450-1514) and its literary and political implications. The transition from Petrarchism to Hermetism and Allegory is analysed in the Libro de la Methamorphosi, as well as the substitution of Sannazaro's bucolic code for the functional literary qualities of the Parthenopean Mythology.

Keywords: Petrarchism, Cariteo, eclogue, Sannazaro, Parthenopean Mythology, Humanism in Neaples and Ischia, politics and poetry. 


\section{Poi ch'era Napol senza la mia Luna \\ (Endimione, CXLVI, 11).}

I acopo Sannazaro incluyó en la Arcadia (prosa II, 8; prosa XII, 48-53 y en toda la égloga XII, de la que es el interlocutor principal) a su colega académico y amigo Cariteo. Barbiellini Amidei (1999: 18) sostiene que es relevante y significativo el espacio concedido por Sannazaro a Cariteo en dicha composición. En su opinión, de la égloga XII se deduce un claro vínculo entre Pontano y Cariteo "per l'assidua imitazione dei classici realizzata dal catalano, e per il suo strenuo umanesimo volgare». Sannazaro llama al poeta Barcinio, en recuerdo a su origen barcelonés: Benet Garret (1450-1514) se estableció en Nápoles desde su temprana juventud en busca de fama y fortuna. De sus orígenes familiares no se ha encontrado documentación alguna hasta el momento. Algunos estudiosos como Parisi (1997) y Querol Coll (2004) apuntan la hipótesis de que su linaje barcelonés procedía de una ilustre familia Garret de Tortosa, que durante el siglo XVI fructificó en personajes influyentes e instruidos, como Esteve Garret.

Estudios recientes (Soranzo 2014) señalan con acierto la búsqueda de identidad cultural por parte de la dinastía catalanoaragonesa de Nápoles. La ciudad es durante el siglo XV confluencia del mundo, un lugar de oportunidades para cortesanos y artistas, que son reclutados por los propios reyes. Pontano provenía de Umbría, Garret era catalán. En este sentido es significativa la "anomalía” de Nápoles durante el Renacimiento, a diferencia de Florencia y Venecia, que contaban con un tejido de talento local.

Garret vivió en primera persona el devenir trágico del reino en la segunda mitad del Quattrocento. Ocupó cargos importantes como el de secretario y ministro en la corte napolitana, especialmente durante el breve reinado de Ferrandino (1495-1496), modelo del príncipe del Renacimiento; sufrió la confiscación de todos sus bienes con las invasiones de Carlos VIII y de Luis XII de Francia y se vio forzado al exilio. Permaneció en Roma desde 1501 a 1503, hasta que las tropas de Gonzalo Fernández de Córdoba al servicio del Rey Católico liberaron Nápoles del dominio francés. Conviene señalar que, a diferencia de la huída a Francia de Pontano y de Sannazaro, Garret elige Roma. Allí gozó del apoyo de su amigo el humanista Angelo Colocci, pues nos ha llegado noticia de ello (cf. Pèrcopo 1892, I: XXXVIII-XXXIX, CCXVIIICCXXVII). Pero, además, creo que muy probablemente también contó con la ayuda del círculo de catalanes y valencianos perteneciente al entorno de Alejandro VI, papa Borja. Nápoles es liberada en abril de 1503. El papa muere en agosto de aquel ańo y en Roma reina la confusión. Cariteo decide regresar.

A su vuelta a Nápoles, es recompensado por Fernández de Córdoba con el cargo de gobernador del condado de Nola en el mismo año de 1503. Este cargo incluía una discreta renta anual y le fue concedido a modo de rehabilitación 
política, como pago quizás a los servicios prestados secretamente al rey Fernando. El profesor Ivan Parisi (1997) apunta la hipótesis de que Cariteo fue informador puntual del Rey Católico desde su posición de alto funcionario de la corte de los reyes de Nápoles.

En este punto quisiera insistir en el interés que suscita el análisis de las alusiones a Fernando el Católico contenidas en la obra de Benet Garret, en concreto, en algunos sonetos de su cancionero y en los cánticos de la Methamorphosi. Si bien es claramente manifiesta a lo largo de su obra la devoción por los reyes aragoneses de Nápoles -baste señalar su gran canción de corte virgiliano y neoplatónico conocida como Aragonia, en que se ensalza a toda la dinastía entronizada desde la conquista de Alfonso el Magnánimo (cf. Segarra Añón 1997; Scarlatta Escrich 2003)-, no podemos pasar por alto el elogio innegable a Fernando de Aragón, para quien reserva el epíteto de "Aragonio sol» en el soneto IV de la edición de su obra completa, publicada en Nápoles por S. Mayr en 1509:

\section{Ad quanto un cor gentile ama e desia le mie speranze e voglie hor son si pronte, chio spero anchor di lauro ornar la fronte nel dolce luogo dove io nacqui pria. Primo sarò, chén l'alta patria mia condurrò d'Aganippe il vivo fonte, venerando di Giove il sacro monte, se morte dal pensier non mi disvia. E'n su la riva del purpureo fume io vo' constituire un aureo templo, in memoria del mio celeste lume. \\ Et tu, Aragonio sol, ch'or io contemplo, sarai del primo altare il primo nume, ché de divinità sei primo exemplo.}

Coincido totalmente con Consolo (1978: 92) y Parenti (1993: 15) que indicaron, aunque sin ulteriores consideraciones, que el destinatario del soneto es Fernando el Católico. Descarto la posición de Pèrcopo (1892, II: 9-10) y Fenzi (2002: 135), que atribuyen el epíteto a Ferrante I de Nápoles, muerto en 1494. Consideran que el soneto fue escrito antes de esa fecha y colocado en cuarta posición en la edición de 1509.

A mi entender todo el verso "Et tu, Aragonio sol, ch'or io contemplo» me parece clave en la datación e interpretación del soneto, no solo el epíteto dedicado al rey, que centra la atención de Consolo y Parenti. Las referencias a Barcelona ("l'alta patria mia»), Montjuïc («di Giove il sacro monte») y el río Llobregat («purpureo fiume»), como ya ha sido comentado ampliamente por la crítica, resaltan el anhelo del regreso a la primera patria con el laurel de la gloria poética y el deseo de erigir un templo al recuerdo de su amada. Sobre este asunto Sannazaro en la Arcadia, XII, 37-39 exclama: "Questo è l'altar che in tua memoria edifico; I quest'e 'l tempio onorato, e questo è il tumulo / in chio piangendo il tuo bel nome amplifico", versos en los que el poeta alude a la 
construcción de un templo dedicado a la memoria de Filli, contrafigura lírica de Adriana Sassone, esposa de Pontano, muerta en 1490.

En el caso de Cariteo, el templo de la memoria estará dedicado a Luna, su amor ausente desde 1492, en cuyo altar mayor se venerará también la imagen del rey Fernando el Católico, soberano de la Corona de Aragón. La construcción de un templo poético en Barcelona en que se venere la figura de un rey napolitano, y por tanto extranjero, se hace difícil de entender ${ }^{1}$. Barbiellini Amidei (1999: 115-117) señala el gusto del Renacimiento por la construcción de templetes, capillas y monumentos relacionados con la poesía: en el caso de Nápoles cita como ejemplos contemporáneos de Cariteo más destacados la Cappella Pontano, erigida entre 1492-1494 y la iglesia de Santa Maria del Parto a Mergellina, cuya advocación fue inspirada sin duda por la obra De partu Virginis de Sannazaro, su fundador en 1504.

La insistencia en el regreso a Barcelona, visible en la accumulatio de elementos que hacen constante referencia a la patria natal, con el propósito de ofrecerle a ella y solo a ella el honor poético alcanzado durante toda una vida; la intención de erigir un templo de amor y poesía allí, todos estos deseos son expresados delante del «sol de Aragón, que yo ahora contemplo», quizá en presencia del rey. La fecha de composición del soneto me parece tardía, muy posterior a 1494, corresponde a la madurez y últimos ańos de Garret. Me inclino a pensar que puede fecharse entre 1506-1507, período coincidente con el viaje y la estancia de Fernando el Católico en Nápoles e Ischia, donde visitó a su tenaz aliada Costanza d'Ávalos ${ }^{2}$.El viaje a Nápoles del rey emprendido en septiembre de 1506, dos ańos después de la muerte de Isabel la Católica (Vecce 2013: 45; Kamen 2014: 54), resultó fundamental para la historia inmediata del reino: depuso a Fernández de Córdoba, ferviente defensor de los intereses de Castilla, del poder en Nápoles; designó al catalán Ramon Folc de Cardona (Bellpuig 1467- Nápoles 1522) como virrey de Sicilia en 1507 y le aupó en su cursus honorum hasta convertirlo en 1509 en virrey de Nápoles ${ }^{3}$.

Cariteo podría haber escrito el soneto IV, con motivo de la llegada del rey a Nápoles, como prueba de su renovada fidelidad y en homenaje a su tierra natal, donde quería ser enterrado.

Me parece destacable el uso del verbo contemplo, en contraposición al soneto CCIV, en el que Cariteo encarga un mensaje para el Católico a un caballero amigo, también catalán, Joan Castell. Consta que Castell formaba parte de la

1. Para el análisis del tema del templo de la memoria poética en la obra de Garret y la notable presencia de Horacio en ella, cf. Segarra Añón 1991 y 1994; Parisi (reseña de Segarra Añón 2007) 2010.

2. Para el estudio de Costanza d'Ávalos en la poesía de Cariteo, cf. Segarra Añón 2007, 65-70; para las relaciones familiares, políticas y literarias que estableció desde su posición de gobernadora de Ischia, remito a Guerra Medici 2009, 115-162; sobre su importancia en la corte de Ischia durante el Renacimiento, cf. Castagna 2014.

3. Sobre la figura histórica de Ramon Folc de Cardona y su espléndido mausoleo renacentista transportado desde Nápoles a Cataluña y actualmente ubicado en la Iglesia parroquial de Bellpuig, cf. Yeguas i Gassó 2009. 
comitiva del virrey Ramon Folc de Cardona en $1512^{4}$. Tenía que partir de viaje a Espańa y presentarse en la corte:

Castel, fundato in chiaro, alto intelletto,
di cor viril munito e ben construtto,
hor che fa quel gran Re, dal ciel produtto,
per la fede augmentar da Christo eletto?
Digli, quando sarai nel suo conspetto,
che, se vuol di vertù coglier il frutto,
et conservarlo intègro o incorrutto,
a l'honor de le Muse haggia rispetto.
Io so che, poi di suoi longevi tempi,
andrà nel ciel, poi c'haggia tolto il santo
sepulcro di Ihesù da man de gli empi;
ma, se sonan suoi gesti in dolce canto,
di sé lasciando memorandi exempi,
optenerà tra Regi il primo vanto.

Cariteo insiste en la idea de que el caballero Castell transmita sus palabras cuando se encuentre delante del rey ("quando sarai nel suo conspetto»), a quien esta vez llama "gran rey», y loa en calidad de garante de la cristiandad, cual nuevo cruzado, al que le pide que tenga en cuenta a los poetas... y a él. En este soneto me parece evidente el ofrecimiento de Garret hacia el Católico: quisiera ser él el poeta escogido para redactar un poema épico a la altura de las Res gestae de Fernando de Aragón.

Además de los sonetos IV y CCIV analizados, el rey también es elogiado por Cariteo en CXLVI (Pèrcopo 1892, II: 174-175) y CXCV, (ibidem: 233234), cuyo último terceto encierra el sentimiento de agradecimiento al rey por los honores concedidos a Nápoles y al destinatario del poema, el noble jurisconsulto Ludovico Montalto: «Devem noi ringratiar senza misura / quel Re, che ne dimostra i tuoi gran pregi, I a Napol gratia, a te facendo honore». El soneto puede fecharse en 1505, cuando el personaje recibió del virrey Ramon Folc de Cardona privilegios y posesiones en nombre de Fernando. A esta recompensa se refiere Cariteo. Volveremos más adelante sobre el interés que despierta la poesía épica en Cariteo en la última etapa de su producción, a partir del período 1501-1503, al cual petenecen los cuatro cánticos de las Methamorphosi.

En los últimos años de su vida Benet Garret se adaptó al nuevo gobierno e intentó hacerse un hueco en la corte fastuosa del virrey Cardona. Prueba de ello es el soneto CCXI, escrito por nuestro poeta con motivo de la entrada triunfal del virrey en la ciudad el 24 de octubre de 1509. Parisi (1997) afirma que precisamente entre 1508 y 1509 Cariteo escribe a Fernando el Católico con el propósito de conseguir una compensación por los servicios prestados como informador del rey durante el reinado de Ferrandino, poco antes de la primera invasión francesa, la de Carlos VIII. Insisto en la importancia del período comprendido entre 1501 y 1509 en la vida y la obra de Cariteo. Son

4. Para el estudio de personajes relevantes de la Corona de Aragón en Nápoles, a quienes Garret dedica poemas, remito al capítulo «Habitants del cançoner», en Segarra Añón 2007, 53-63. 
años que la literatura crítica sobre el autor ha tendido a descuidar, junto a su poesía de corte narrativo escrita in terza rima. Señalé esta circunstancia al reseñar el libro de Parenti (1993) dedicado a Garret (Segarra Añón 1998: 90). Es el caso del Libro de la Methamorphosi, en concreto el cántico IV, que nos proponemos analizar. Una primera aproximación a la obra la publiqué en 2007: «Un viatge vers el desencís», en Endimió retornat. Estudi sobre Benet Garret, "Il Cariteo", 121-128; para estudios posteriores sobre las Metamorfosi de Cariteo, cf. Del Frate, 2014 y Cantalupi, 2015.

La vida de Garret transcurrió en Nápoles, pero nunca abandonó la idea de volver a su tierra natal coronado como poeta, una auténtica constante que recorre toda su obra. Fenzi (2002) indica la posibilidad cierta del retorno a Barcelona, como ya hemos señalado anteriormente al analizar el soneto IV. No sabemos si el ansiado regreso al fin se produjo; sin embargo, es curioso constatar que no tenemos noticia alguna de su sepultura en Nápoles, a diferencia de los ricos sepulcros de sus colegas académicos coetáneos, como el de Sannazaro, que se encuentra en la iglesia de Santa Maria del Parto a Mergellina ${ }^{5}$.

Cariteo ha pasado a la historia de la literatura italiana por ser autor de un bellísimo cancionero de corte petrarquista titulado Endimione. La historia del apuesto pastor de Latmos, Endimión (cuyas principales fuentes grecolatinas son: Plat. Fedón, 72 c; Cic. De Fin. 5, 20, 25 y Tusc. 1, 38, 92; Paus. 5, 1, 2; Apd. Bibl. 1, 7, 5; Apol. Rod. Arg. 4, 57; Hig. Fab. 271) de quien se enamoró Selene, es decir, la Luna, constituye el punto de partida de la experiencia poética del autor, que retoma el mito y lo reelabora para convertirse él en Endimión, amante frustrado de su dama, a quien reserva el senhal de Luna.

La recepción de la historia de Endimión durante el Renacimiento abraza la literatura, la iconografía y el pensamiento filosófico. El mito, a partir de la circulación del cancionero de Garret, parece haber echado raíces en la cultura napolitana. Me parece importante subrayar esta circunstancia en relación a los estudios dedicados a la fortuna de la obra de Cariteo (Parenti 1993, «La fortuna»: 112-145; Segarra Añón 2007, "Cariteo i Gutierre de Cetina»: 135139), todos ellos circunscritos hasta el momento al ámbito especializado de la filología y de la historia de la literatura. La huella del poeta catalán, sobre todo en cuanto al motivo del nocturno, por cuya elegante recreación y acompańamiento musical fue célebre, creo que se puede reseguir en el hecho de que los amores del pastor, que Cariteo entronizó como personaje literario de primer orden a principos del siglo XVI, se incorporan paulatinamente al mundo de la música culta a través del género de la serenata y gozan de cierta fama durante el siglo XVIII. Desde Nápoles las serenatas tituladas L'Endimione se extienden a las principales cortes europeas, con una notable presencia en la

5. Cf. Iacopo Sannazaro, De partu Virginis, ed. C. Fantazzi y A. Perossa, Florencia, Olschki, 1988. La iglesia se completó en 1529. Se encuentra ubicada en el barrio de Chiaia en la zona de Mergellina. Pronto se convirtió en lugar de oración para las mujeres embarazadas o para las que deseaban concebir. En ella se encuentra el sepulcro de Sannazaro, que incluye el busto del poeta y la inscripción de su nombre académico, Actius Sincerus. 
corte de Madrid. Alessandro Scarlatti (1660-1725), que pasó la mayor parte de su vida como maestro di cappella de la corte española de Nápoles, compone en 1705 una serenata titulada Endimione e Cintia, apelativo este último sinónimo de Diana o Luna. A partir de la obra citada de Scarlatti se suceden en Nápoles serenatas y cantatas dedicadas al mito de Endimión compuestas por Niccolò Conti (1752), Niccolò Jommelli (1759), Nicola Conforto (Nápoles, 1763 y representada en Madrid en 1764), Giuseppe Sigismondo (1765). Una versión destacable es L'Endimione compuesto conjuntamente por el catalán Manuel Pla y el napolitano Francesco Montaldi y estrenada en Madrid en 1752. Kleinertz (2003: 101-102) señala el elenco completo de compositores que recrean el mito de Endimión en Italia y en toda Europa a lo largo del s. XVIII.

La figura del pastor amante de la Luna simboliza el paradigma de la vida escindida en tres caminos: la vida sensual, la vida activa o política y la vida contemplativa (Gandolfo 1978: pass.; Barbiellini Amidei 1999: 57-72 analiza en profundidad los elementos neoplatónicos y ficinianos en la obra de Cariteo).

El personaje de Endimión, modelado por el poeta petrarquista Cariteo, se reconoce víctima de Eros. En cambio, la interpretación cristiana del mito tiende a la identificación entre amor, encarnado en el fiel Endimión, y castidad, representada por la diosa Diana, es decir, la Luna, asimilada a la figura de la Virgen. Endimión también es reconocido en la época como hombre político o cortesano enamorado como nuestro poeta ${ }^{6}$.

El erudito editor de la obra de Cariteo, Erasmo Pèrcopo (1892) ya señaló que la verdadera Luna se esconde tras los siguientes versos del soneto XVIII del Endimione, en que el autor realiza una variatio expresiva del patrón petrarquista (Petrarca, Canzoniere, 202: 1-2 : «D'un bel, chiaro e vivo ghiaccio / move la fiamma che mincende e strugge») para aludir a la identidad de su dama. Y el poeta dice así:

\section{D'un monte chiaro e pien di bianca neve esce la fiamma ardente che mi strugge}

(Endimione, XVIII, vv. 9-10).

Diversas son las hipótesis señaladas por la crítica sobre la dama cantada en estos versos. La variatio respecto al texto de Petrarca en la palabra monte ha dado lugar a la identificación de la enamorada con una mujer perteneciente al noble linaje napolitano de Chiaromonte. Esta hipótesis es la más defendida por los estudiosos de la obra de Garret. Parenti, que en su monografía dedicada a Cariteo en 1993 profundizó un poco más en el tema, apuntó que el nombre de la dama probablemente era Diana o Dianora, variante de Eleonora, que remite directamente al senhal Luna del cancionero de Cariteo, y descartó la posibilidad de que la dama fuera como él, de origen catalán, tal vez una Montcada, detalle que, según Parenti, Cariteo no hubiese omitido en sus rimas.

6. Sobre esta cuestión, cf. Agapiou 2005, cap. IV «Endymion sive Gratiosus». La autora incide en el hecho de que este simbolismo fue muy popular en la Inglaterra isabelina. La reina tenía su "Endimión" particular o cortesano enamorado. 
La crítica se ha centrado, como he dicho, en la primera parte del verso y ha obviado la segunda: «e pien di bianca neve». Es preciso advertir que Garret siente predilección por los juegos de palabras, por la latinización, por la etimología, cierta o inventada (cf. por ej. su Monte di Giove, es decir, 'Monte de Júpiter', en alusión a Montjuïc), cuando cita los nombres de los destinatarios de sus poemas, tendencia esta muy notable en particular en la segunda parte del cancionero. Por ello me inclino a pensar que conviene tener presente el verso entero, "D'un monte chiaro e pien di bianca neve», para indagar en la identidad de Luna.

Me gustaría poner sobre la mesa algunas consideraciones sobre la cuestión: la rama napolitana, pequeña, del linaje Chiaromonte, variante de Chiaramonte, tiene su origen en Sicilia. Durante el siglo XIV un tal Andrea Chiaramonte de Messina se rebela contra el dominio catalán de la isla. El rey pacificó la rebelión en 1398 y las tierras de la familia Chiaramonte pasaron a los nobles catalanes Guillem Ramon Montcada y Bernat Cabrera, quienes cambiaron la toponimia de las posesiones de los traidores por el apellido Montechiaro, conservado aún en la denominación de la localidad siciliana de Palma di Montechiaro. Igualmente el apellido Riccio di Montechiaro aparece documentado en el siglo XV en Nápoles, en la figura de un noble caballero y militar, consejero del rey Alfonso I de Nápoles, V de Aragón, el Magnánimo. ${ }^{7}$

Asimismo, en Sicilia se rastrea la presencia de un noble apellido, Montalbo, del que deriva el ducado de San Martino Montalbo, muy ligado durante el siglo $\mathrm{XV}$ a la dinastía catalanoaragonesa establecida en Nápoles. Montalbo podría ser la versión a la que alude la segunda parte del verso de Cariteo «(monte) pien di bianca neve», del latín albus, 'blanco', y, por tanto, Montalbus. Luna podría ser, tal vez, una noble dama napolitana de ancestros sicilianos llamada Dianora (o Eleonora) Montechiaro o Montalbo, que, sin duda alguna, frecuentó la corte de Ischia y de allí partió casada, en octubre de 1492, con rumbo a España, según se deduce del análisis de algunas composiciones del Endimione (Canzone XI y XII, Pèrcopo 1892, II: 143-147; 152-155).

Los numerosos estudios sobre el poeta se han ocupado con detenimiento del análisis y la evolución de su petrarquismo, así como de la adopción del modelo toscano como referente culto (Fenzi 1970; Santagata 1979; Parenti 1993; Segarra Añón 1998 y 2007; Barbiellini Amidei 1999), que podía estar a la altura de las creaciones neolatinas de humanistas tan influyentes como Pontano. La elección del volgare obedece en este caso, a mi juicio (concuerdo con Trillini 2013), a motivos estrictamente literarios y no políticos (como sostiene Kennedy 2002).

Sin embargo, los cánticos de Cariteo escritos in terza rima, de carácter narrativo, mitológico y alegórico, como los cuatro cánticos del Libro de la Methamorphosi, a los cuales dediqué un capítulo de mi monografía sobre el poeta (Segarra Añón 2007: 121-128) y que me parecen fundamentales para

7. Sobre esta noticia remito a Angelo di Costanzo (1839), Storia del Regno di Napoli, Napoli, Borel e Bompard. 
el estudio y la interpretación de la obra de Garret a partir de 1503, han sido objeto de atención por los italianistas solo muy recientemente (Del Frate 2014 y Cantalupi 2015).

Escritas muy probablemente en el período de su exilio romano, del 1501 al 1503, las Metamorfosis de Cariteo suponen un giro decisivo en la producción del autor hacia la poesía narrativa y hacia su creciente interés por la poesía épica. Recordemos, como hemos señalado anteriormente, que en el soneto CCIV del Endimione, Garret ya se había ofrecido como posible cantor de las Res gestae de Fernando el Católico. Los cánticos de las Metamorfosis constituyen, además, un claro retorno del autor al cobijo intelectual de la Academia Pontaniana, pasados ya los días de su experiencia lírica petrarquista. En ella, BarcinioCariteo había adoptado el alter ego del pastor Endimión y se había sumado así al código bucólico y amoroso propuesto por Sannazaro-Sincero en la Arcadia. En la obra de Sannazaro dicho código se sustenta con solidez en la tradición bucólica grecolatina, de tal modo que consigue así ligar su Arcadia estrechamente al humanismo napolitano. El poeta de Mergellina se aleja del estilo poco "depurado" de las églogas compuestas por Pietro Iacopo De Iennaro y Giovan Francesco Caracciolo, con quienes compartió sus primeras rimas de juventud (cf. Vecce 2013: 14-15 y 20).

Las Metamorfosis de Garret suponen un cambio en dicho código. La mitología partenopea se erige en relevo necesario en la elaboración de una poesía que hunde sus raíces en los acontecimientos políticos que se sucedieron en Nápoles a partir de 1503, con la liberación del dominio francés y la conquista del reino por parte del Rey Católico. Y también es dicha mitología la que permite al poeta, en un plano alegórico, traspasar los límites del género y hablar desde la voz femenina a través del personaje de la ninfa marina o sirena Inárime, también llamada Enaria, y de numerosos exempla de heroínas literarias y legendarias de la antigüedad, como veremos en el cántico cuarto y último de las Metamorfosis.

Con una extensión de 245 versos, el cántico cuarto cuenta la desgraciada historia de Inárime o Enaria, por la que se convirtió en la isla volcánica de Ischia y le dio nombre. El apelativo de Inarime aparece documentado en Virg. Aen. 9, 716: "Inarime Iovis imperiis imposta Typhoeo»; Plinio 3, 82 y Ovidio M. 14, 89. En cambio, la referencia a Ischia con el nombre de Aenaria se encuentra en Cic. Att. 10, 13, 1 y Liv. 8, 22, 6: «in insulas Aenariam et Pithecusas»; las principales fuentes clásicas utilizadas por Cariteo en el cántico IV son: Ovidio, M. 1, 577-585; 6, 412-423; Virgilio, Aen. 4, 537-538; 595-596; Lucrecio, IV, 1169-1171.

El cántico empieza con el poeta que, al despuntar el día, se dirige a la desembocadura del río Sebeto, emblema humanístico de la ciudad de Nápoles. El rico imaginario mitológico de Sebeto contaba con un texto de referencia, el Lepidina de G. Pontano; bello epitalamio del río con la ninfa Parténope, es decir, Nápoles, con la participación de ninfas y otras divinidades que aluden a distintos lugares del golfo napolitano. Y Garret dice así: 
Allí confiesa encontrarse angustiado, insomne, triste por la pérdida de su amor:

\section{Perduto il bene, ond'io non fui più lieto}

(Met. IV, 12).

Es preciso resaltar que en la edición de Erasmo Pèrcopo (1892), todavía hoy la única edición filológica de referencia de la obra completa de Garret, el erudito italiano indica que este verso apunta probablemente a la muerte del rey Ferrandino o al noble Alfonso d'Ávalos, a quienes nuestro poeta se encontraba muy unido. Su interpretación me parece errónea, puesto que más adelante, a partir del verso 30, la fábula de Inárime o Enaria nos desvela el juego de equivalencias establecido por Cariteo: la historia de amor entre Inárime (Ischia) y Febe (denominación griega equivalente a la antigua diosa Diana, identificada con la Luna) remite directamente a los amores entre el pastor EndimiónCariteo y Luna, la dama cantada en su cancionero petrarquista.

En el lugar ameno donde Sebeto se une al mar, nuestro poeta se queda dormido y en sueños recibe la visita del río, con quien dialoga a lo largo del cántico. Sebeto cuenta la trágica fábula de Inárime-Enaria y Febe (Met. IV, 25-230), por la que la primera, a causa de la pena, se secó, ardió, explotó y se convirtió «in duro scoglio» (v. 30), en Ischia.

El punto de inflexión en que la tierna amistad entre las dos jóvenes se troca en drama aparece en el verso 76 , fundamental y controvertido para la interpretación de todo el cántico:

\section{Phebe volse lasciar l'Enaria corte}

(Met. IV, 76).

Es decir, 'Febe quiso abandonar la corte de Ischia'.

El abandono de Febe-Luna de la corte de Ischia fue interpretado por E. Pèrcopo (1892, II: 329) como una alusión evidente al viaje emprendido a España por Luna, el amor de Endimión-Cariteo, fechado el 10 de octubre de 1492. Cantalupi (2015: 35-36) se muestra contraria a la interpretación de Pèrcopo e indica que, a tenor de los versos 55-57:

Era il dolore alquanto mitigato
de la comune Italica pernicie,
scesa dal ciel per implacabil fato

(Met. IV, 55-57).

Se podría relacionar la partida de Febe con la marcha desde Ischia de Isabella del Balzo, esposa del exiliado rey Federico de Nápoles. Así pues, según Cantalupi, el verso 76 de Cariteo, que incide en la separación de Inárime y Febe, debe entenderse como referencia a la separación de los monarcas Federico e Isabella, y aludiría a hechos acontecidos mucho después de 1492. 
Federico I de Nápoles fue proclamado rey en 1496 y en 1501 fue depuesto y relegado a Ischia por Luis XII de Francia, quien se apoderó de Nápoles de 1501 hasta 1503, año en que Fernando el Católico reconquista el reino. Desde Ischia el rey Federico fue conducido a Francia como prisionero, donde murió en 1504. La reina le siguió al exilio poco después.

La interpretación de Cantalupi es atractiva, pero en ella encuentro dificultades. Por un lado, en el verso 153 del cántico IV Inárime, «infelice amante e dolorosa» (v. 152), llama desesperada a la amada con el vocativo Luna: "Ai!, Luna, ai!, ai! -chiamar non cessa», reza el verso. Me parece dudoso que el poeta utilice directamente el senhal del Endimione, reservado a su enamorada, para referirse a la reina, Isabella del Balzo. Por otro lado, tras el largo lamento de Inárime por la partida de Febe, a partir del verso 185 comparecen en el relato todas las sirenas del golfo napolitano, excepto Parténope (Nápoles) que ahora se encuentra «in servitù, di vita stanca» ('sometida, cansada de vivir', v. 190). Entre ellas se encuentra la sirena Actia Mergellina, que toma la palabra para consolar a Enaria. La alusión a Sannazaro, como ya señaló Pèrcopo (1892, II: 335), es clara: «Actia» se refiere al apelativo académico de Sannazaro, Actius Sincerus, y "Mergellina» se refiere a la zona de la ciudad donde el autor de la Arcadia tenía su famosa villa. En realidad Sannazaro también se exilió. Vecce (2013: 38) añade al respecto: «Un esilio vero e doloroso, non solo immaginato come quello in Arcadia; e a Napoli aveva anche lasciato il manoscritto autografo dell'Arcadia».

Creo pues improbable que si el cántico IV de Cariteo quiere hacerse eco, como afirma Cantalupi, de aquel triste episodio que también sufrió el amigo de Garret, sea presentado él como interlocutor de Inárime, el que se queda junto a las demás sirenas napolitanas en Ischia para consolarla. Sannazaro también formaba parte de la comitiva que partió con el rey Federico, a la que más tarde se unió la reina. No creo que Garret hubiese omitido el infortunio de su colega académico en el cántico IV si su intención hubiese sido reflejar en él la disolución y el exilio de la corte de Ischia en aquel preciso episodio.

A partir de 1504 Ischia recuperó su posición privilegiada dentro del reino y durante el gobierno del virrey Ramon Folc de Cardona se mantuvo como activo cenáculo humanístico. Consta la presencia de Cariteo en ella (cf. Giordano 1906; Torras Tilló 2010; Castagna 2014) junto a otros poetas, intelectuales y artistas como Sannazaro, Giovanni Battista Musefilo e incluso Michelangelo Buonarroti en 1509. En ese período se instaló en el castillo de Ischia la célebre poetisa Vittoria Colonna, junto a su noble esposo Ferrante Francesco d'Ávalos, quien en 1512 participó en la batalla de Ravenna a las órdenes del virrey.

Me gustaría incidir en una cuestión, que he apuntado anteriormente, y de la cual los estudios recientes que comentan el cántico IV de las Metamorfosis no se han ocupado (Del Frate 2014; Cantalupi 2015). Se trata, a mi entender, en primer lugar, del traspaso del código bucólico-amoroso al mitológico, acometido por el poeta a la hora de encajar el relato en el texto creado por medio del cambio de género. $Y$, en segundo lugar, la adopción de la voz femenina 
como voz lírica preponderante, que Cariteo introduce en el dramático lamento de Inárime (vv. 110-127 y 158-181) y por extensión a lo largo de todo el cántico IV.

En efecto, el código bucólico establecido entre Barcinio-Cariteo y SinceroSannazaro, que mantiene un juego de correspondencias y complicidades académicas entre la Arcadia y el Endimione, se troca en el Libro de la Methamorphosi en el recurso a la mitología y al traspaso de género: ahora es Inárime (alter ego de Cariteo) quien dialoga con otra sirena del golfo napolitano, Actia Mergellina (alter ego de Sannazaro). La tristeza de Inárime no encuentra consuelo en las palabras de Mergellina (vv. 191-196):

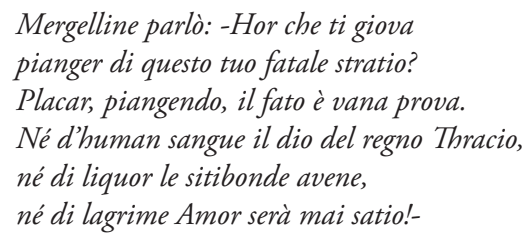

Asimismo, a partir del verso 30, en que el poeta introduce la historia de Inárime-Enaria en boca del río Sebeto hasta el final del relato por parte de este (v. 230), a lo largo de 200 versos de los 245 de que consta el cántico IV, Cariteo adopta como eje que articula la fábula exclusivamente exempla femeninos tomados de la antigüedad clásica. A continuación, los indico en la tabla siguiente por orden de aparición en el cántico y señalo también todos los versos en que aparecen citados:

\begin{tabular}{|l|l|}
\hline PERSONAJE FEMENINO & Met. IV \\
\hline Inárime-Enaria & $30,49,58,104,131,230$ \\
\hline Febe-Luna & $76,79,102,153$ \\
\hline Medea & 115 \\
\hline Ariadna & 118 \\
\hline Helena de Troya & 118 \\
\hline Europa & 119 \\
\hline Dido (abandonada) & $123-127$ \\
\hline Filomela y Procne & $143-145$ \\
\hline Hele & 181 \\
\hline Sirenas del golfo napolitano & $185-187$ \\
\hline Actia Mergellina (Sannazaro) & $187-191$ \\
\hline Musas de Summonte & 203 \\
\hline Musas de Sincero (Sannazaro) & 203 \\
\hline Comitiva de Pontano (Academia) & 205 \\
\hline
\end{tabular}

En el verso 110 comienza el lamento de Inárime, que ve alejarse desde la playa la nave en la que se marcha Febe (vv. 102-103: «Fu posta l'aurea Phebe 
in l'alta nave, / qual martyr tratto al duro, impio supplitio»). Entonces Inárime toma la palabra y su voz nos recuerda en primera persona la belleza de la amada a quien compara a Medea, Ariadna, Helena de Troya y a Europa. Duda en correr tras ella, como le ocurrió a la desventurada Dido, reina de Cartago, abandonada por Eneas, y aquí Garret recrea los hermosos versos de Virgilio (Virg. Aen. 4, 537-538 y especialmente 595-596: "Quid loquor? Aut ubi sum? Quae mentem insania mutat? / infelix Dido, nunc te facta impia tangunt?») y los pone en boca de la sirena:

Chi mi vieta seguirla ove che sia?
Qual tema vinse mai tanto desio?
Che parlo?.. O dove sono?... O qual follia
rivolge de furor la mente offesa?
Se'l fato per me sol chiude la via!...

(Met. IV, 123-127).

Más adelante, en el verso 143 Cariteo compara el llanto de Enaria con las quejas dolorosas de Tereo, convertido en abubilla a causa de su crimen contra las hermanas Filomela y Procne (Ov. M. 6, 671-676), y en el verso 181 aparece citada Hele, personaje mitológico femenino del cual el Helesponto recibe su nombre, hoy actual mar de Mármara.

A partir del verso 185 todas las sirenas del golfo de Nápoles, exceptuada Parténope, su reina, acuden a consolar a Inárime: comparecen las sirenas de Amalfi, de Sorrento, la "dolce Platamonia, bella e bianca» (v. 186) y Actia Mergellina, sirena que personifica, como hemos indicado, al amigo Sannazaro. Se establece entonces el diálogo entre Mergellina e Inárime. Esta le pide que cante junto a las demás sirenas su triste caso. Y precisamente en este punto, en el verso 203, Cariteo introduce una ferviente invitación a la Academia: cita siempre desde la voz femenina a las musas de sus colegas Pietro Summonte, Iacopo Sannazaro y a las filas (nótese el uso del femenino schiere), es decir, a la comitiva de académicos presidida por Giovanni Pontano. Y así rezan los versos:

Se voi, Summontie, e voi, Muse Syncere, $i$ nostri amori, in suon dolce e canoro, farete gir tra le Pontane schiere

(Met. IV, 203-205).

El objetivo de Cariteo es brindar a la Academia el episodio de Inárime y Febe en calidad de materia poética. En estos tres versos, creo, se encuentra sintetizada una renovada adhesión del autor al programa del humanismo napolitano. En esta invocación a la Academia también se lee no una renuncia, pero sí un cierto alejamiento de Cariteo respecto al estilo de la poesía petrarquista y cortesana, que tanto éxito le reportó en el pasado. No se trata, en mi opinión, de un repudio de dicho estilo, sino más bien un repliegue personal y literario, la búsqueda de nuevos horizontes de creación, sin duda encaminados al cultivo de la poesía épica o narrativa. Esta actitud coincide con las tensas circunstancias históricas que vivía en aquel momento el Reino de Nápoles y las consecuencias 
que originaron en la vida de Garret. La exclusión de la sirena Parténope del cántico IV constituye un símbolo inequívoco del devenir dramático de los tiempos.

Tras la invocación a la Academia, Cariteo concluye el cántico con la descripción de la metamorfosis de Inárime (vv. 212-226), el llanto, la maldición del lugar y huída de las sirenas (vv. 227-229), el fin del relato de Sebeto (v. 230: "D'Inarime io tho detto il caso amaro») y un diálogo final entre la voz lírica de Cariteo, que ya ha dejado atrás la voz femenina, y el río. El poeta le pregunta por qué razón añade aquel con la tragedia de la sirena más tristeza a su antigua pena (v. 234: "giungere a le mie antique hor nova pena»). Este verso a mi entender constituye una autocita en sí mismo, un recuerdo al cancionero, en que «las antiguas penas de amor» son las de Endimión-Cariteo por Luna. En las últimas palabras de Sebeto no hay consuelo para el poeta que, tras la marcha del río, se despierta. Y así termina el cántico.

Cariteo escribe las Metamorfosis desde su exilio romano, como ya hemos señalado en páginas anteriores, a partir de 1501. Si bien sufrió la confiscación de sus posesiones por parte de los franceses, su estancia en Roma hay que interpretarla como un tenso compás de espera, no reviste el dramatismo del exilio de la corte napolitana de Ischia. Él, como catalán perteneciente a la Corona de Aragón, es consciente del más que probable cambio de rumbo de los acontecimientos. De hecho, a su vuelta, como ya hemos indicado, es recompensado por Gonzalo Fernández de Córdoba en nombre del rey Fernando, sin duda como prueba de fidelidad y gratitud por los servicios prestados en el pasado. A partir de 1503 Cariteo debe adaptarse a la nueva realidad. Nápoles es gobernada por el virrey designado por el Católico. El poeta, que había llegado a la cumbre de su carrera política durante el breve reinado de Ferrandino, para su propio sustento necesita volver a posicionarse al lado de los poderosos.

Es cierto que en las Metamorfosis Cariteo refleja la tristeza por la pérdida de la gloria pasada (Segarra Añón 2007: 122) y la crítica reciente también lo ha señalado. Así, Cantalupi (2015: 38-39) afirma: «il Libro de la Methamorphosi mostra ancora la fedeltà alla causa aragonese e la fervida passione dell'uomo politico; che è anche un poeta e usa gli strumenti di cui dispone per mitizzare le imprese dei suoi signori» y añade que Garret esconde en su obra la reprobación personal hacia el proceder de los Reyes Católicos y la 'confía a una misteriosa voz sobrenatural' (Cantalupi 2015: 39: "Né nasconde la propria riprovazione per le manovre dei reali di Spagna, solo la affida ad una misteriosa voce soprannaturale»). Conviene matizar en esta afirmación de Cecilia Cantalupi que el control de la política italiana dependía exclusivamente de Fernando y no de Isabel, porque el Reino de Nápoles pertenecía inicialmente al territorio de la Corona de Aragón. De sobras estudiadas son las maniobras y las estratagemas del rey, hábil en la negociación y en el incumplimiento de la palabra dada. Él, como es sabido, será un modelo de príncipe nuevo para Maquiavelo.

Nuestro poeta escribió para la monarquía napolitana descendiente de Alfonso el Magnánimo, pero jamás lanzó una crítica abierta a Fernando en 
sus versos. La «misteriosa voz sobrenatural», que exclama en el cántico I de las Metaforfosis de Cariteo:

\section{Maladetto quel huom, che'n huom si fida}

(Met. I, 57).

'Maldito el hombre que se fía de otro', procedente de una cita bíblica (Jeremías, 17, 5), ha sido interpretada (Pèrcopo 1892; Segarra Añón 2007; Cantalupi 2015) como una reprobación sutilmente velada al Católico, que propició con su política de alianzas la caída del rey Federico de Nápoles a manos de los franceses.

Cariteo aspira a adaptarse a las nuevas circunstancias políticas y a ser tenido en cuenta dentro del círculo del poder virreinal. De ahí, a mi entender, la ambigüedad que se percibe en los cánticos de las Metamorfosis. Una ambigüedad querida, buscada por el autor, en mi opinión. Subyace en ella la antigua fidelidad a la primera patria. Estamos frente a una posición personal e intelectual estratégica, articulada a través de la adopción de la poesía narrativa de corte épico y mitológico como nuevo vehículo de expresión dentro del conjunto de su obra. Gracias a dicha poesía Garret se reafirma como humanista y pretende volver a vincularse a la corte. En él parece no haberse extinguido aún la pasión del poeta y la del hombre político.

\section{Obras Citadas}

\section{Fuentes}

Garret Benet, 1892, Le rime di Benedetto Gareth detto Chariteo secondo le due stampe originali, a cura di E. Pèrcopo, Napoli, Accademie delle Scienze, 2 vols. (vol. I Introduzione, vol. II Rime).

Petrarca Francesco, 1966, Opere, a cura di E. Bigi, Milano, Garzanti.

Pontano Giovanni, 1948, Carmina, a cura di J. Oeschger, Bari, Laterza.

Sannazaro Iacopo, 2013, Arcadia, introduzione e commento di Carlo Vecce, Roma, Carocci editore.

Sannazaro Iacopo, 1988, De partu Virginis, ed. C. Fantazzi - A. Perossa, Florencia, Olschki.

\section{Estudios}

Agapiou Natalia, 2005, Endymion au carrefour: la fortune littéraire et artistique du mythe d'Endymion à l'aube de l'ère moderne, Berlín, Gebr. Mann ed.

Barbiellini Amidei Beatrice, 1999, Alla Luna. Saggio sulla poesia del Cariteo, Firenze, Olschki.

Cantalupi Cecilia, 2015, «Il declino degli Aragonesi di Napoli nel Libro de la Methamorphosi di Benet Garret, il "Cariteo"”, eHumanistalIVITRA, 7. 21-41. 
Castagna Raffaele, 2014, Il Castello d'Ischia "corte reale" e "corte letteraria" del Rinascimento, Napoli, Youcanprit.

Consolo Rino, 1978, «Il libro di Endimione: modelli classici, inventione et elocutione», Filologia e critica, 3. 19-94.

Costanzo Angelo di, 1839, Storia del Regno di Napoli, Napoli, Borel e Bompard.

Fenzi Enrico, 1970, «La lingua e lo stile del Cariteo dalla prima alla seconda edizione dell'Endimione», Studi di filologia e letteratura, I. 9-83.

Fenzi Enrico, 2002, «Et havrà Barcellona il suo poeta. Benet Garret, il Cariteo», Quaderns d'italià, 7. 117-140.

Frate Luana del, 2014, «Scenari infernali e miti sirenici: un'originale commistione tra antico e moderno nelle Metamorfosi di Cariteo", en I cantieri dell'italianistica. Ricerca, didattica e organizzazione agli inizi del XXI secolo, Roma, Adi editore, 20-29.

Gandolfo Francesco, 1978, "Mistica, ermetismo e sogno in una figura allegorica: Endimione», en Il "Dolce Tempo". Mistica, ermetismo e sogno nel Cinquecento, Roma, Bulzoni, 43-75.

Giordano Amalia, 1906, La dimora di Vittoria Colonna a Napoli, Napoli, Tipogr. Molfi $\& \mathrm{~J}$.

Guerra Medici Maria Teresa, 2009, «Intrecci familiari, politici e letterari alla corte di Costanza d'Ávalos», en Donne e scritture del XII al XVI secolo, Bergamo, Lubrina, 115-162.

Kamen Henry, 2014, Brevisima historia de España, Barcelona, Espasa.

Kennedy William J., 2002, "Citing Petrarch in Naples: The Politics of Commentary in Cariteo's Endimione», Renaissance Quarterly, 55: 4. 1196-1221.

Kleinertz Rainer, 2003, Grundzüge des spanischen Musiktheaters im 18 Jahrhundert, vol. II, Ópera-comedia-zarzuela, Kassel, Edition Reichnberger.

Parenti Giovanni, 1993, Benet Garret detto il Cariteo. Profilo di un poeta, Firenze, Olschki.

Parisi Ivan, 1997, "Un informatore del Cattolico: Benet Garret detto il Cariteo», en Benet Garret detto il Cariteo, un umanista catalano alla corte di Napoli: Nuove fonti per uno studio della biografia e delle opere, Tesi di laurea, Roma, Facoltà di Lettere e Filosofia dell'Università «La Sapienza», 1553-1562.

Parisi Ivan, 2010. Reseńa de Segarra Maria-Isabel, 2007, Endimió retornat. Estudi sobre Benet Garret, "Il Cariteo", Barcelona, Omicron, col. "Assaig marbre», 181 p., en Estudis Romànics 32. 427-551.

Querol Coll Enric, 2004, Cultura literaria en Tortosa (siglos XVI y XVII), Tesis doctoral, Barcelona, Departamento de Filología Española de la Universitat Autònoma de Barcelona.

Santagata Marco, 1979, La lirica aragonese. Studi sulla poesia napoletana del secondo Quattrocento, Padova, Antenore.

Scarlatta Escrich Giovanna, 2003, "Cariteo's Aragonia: the language of power at the Aragonese Court», Forum Italicum, 37. 329-344.

Segarra Añón Maria Isabel, 1991, La presència d'Horaci en la cançó de cloenda de l'Endimione. Altres temes sobre la influència dels clàssics a Cariteo, Memòria de llicenciatura, Barcelona, Departament de Filologia Llatina de la Universitat de Barcelona. 
Segarra Añón Maria Isabel, 1994, «El tema del monumentum horaciano en Benet Garret, "Il Cariteo", poeta y humanista catalán en la corte catalanoaragonesa de Nápoles», en C. Codoñer - J.A. González Iglesias (eds.), Antonio de Nebrija: Edad Media y Renacimiento, Salamanca, Ediciones de la Universidad, 505-512.

Segarra Añón Maria Isabel, 1997, «Virgili en l'Aragonia de Chariteo: una lectura política", Anuari de filologia. Studia Graeca et Latina, XX. 67-74.

Segarra Añón Maria Isabel, 1998, "A propòsit d'una lectura sobre Benet Garret "Il Cariteo" (1450-1514). (Giovanni Parenti)», Faventia, 20: 1. 85-94.

Segarra Añón Maria Isabel, 2007, Endimió retornat. Estudi sobre Benet Garret, "Il Cariteo". Antologia poètica traduïda al català a cura de Maria-Isabel Segarra i Israel Clarà, Barcelona, Òmicron.

Soranzo Matteo, 2014, Poetry and Identity in Quattrocento Naples, Surrey, Ashgate ed. Torras Tilló Santiago, 2010, «Molts artistes catalans per als doblers del marquès de Pescara (1523)», Butlletí de la Societat Catalana d'Estudis Històrics, XXI. 103136.

Trillini Matteo, 2013, «Un poeta catalán en la corte italiana de Nápoles. Reflexiones sobre la obra y la lengua de Benet Garret», RLLCGV, XVIII. 95-114.

Yeguas i Gassó Joan, 2009, El mausoleu de Bellpuig. Història i art del Renaixement entre Nàpols i Catalunya, Bellpuig, Saladrigues. 
